\begin{tabular}{|c|c|c|c|}
\hline$\underbrace{\text { INTERNATIONAL }}_{\text {INESEG }}$ & $\begin{array}{r}\text { International } \\
\text { Res } \\
w w\end{array}$ & $\begin{array}{l}\text { urnal of Health Services, } \\
\text { rch and Policy } \\
\text { rgipark.org.tr/ijhsrp }\end{array}$ & \\
\hline $\begin{array}{l}\text { ENGINEERING, } \\
\text { SCIENCE AND } \\
\text { EDUCATION GROUP }\end{array}$ & e-ISSN: 2602-3482 & DOI:10.23884/ijhsrp.2019.4.2.07 & IJHSRP \\
\hline
\end{tabular}

Research Article

\title{
EFFICIENCY, EQUITY, AND EFFECTIVENESS OF MALARIA FUNDING IN UGANDA: MAKING THE CASE FOR REFORMING PUBLIC FINANCING FOR HEALTH
}

\author{
"Vincent Okungu ${ }^{1,2}$ (D), Janine Mans ${ }^{3}$ (D) \\ ${ }^{1}$ School of Public Health, University of Nairobi, Kenya \\ ${ }^{2}$ Philips East Africa, Nairobi, Kenya \\ ${ }^{3}$ Nathan Associates, Inc., Washington, USA \\ "Corresponding author; okungu008@gmail.com
}

\begin{abstract}
Decreasing external funding for malaria requires high burden countries such as Uganda to increase domestic public financing to control and eliminate malaria. This study aimed to examine how the Government of Uganda, in collaboration with development partners and private sources of funding, has directed public resources in the recent past to help address the malaria burden. Data search and collection included national, regional and global reports and global databases. Government reports including National Development Plans, national health accounts, national demographic health surveys, and other reports such as the Uganda Medicines Price Monitor, were included in the review. The findings indicate that government funding for malaria is limited (10\% of the total budget for malaria programming). Households (67\%) are the main source of funds which makes malaria control in Uganda unsustainable. Public allocations are also inefficient with only $30 \%$ of funds allocated for preventive services contrary to global and national malaria control priorities. Evidence of inequity in the implementation of malaria programming is closely linked to poverty and ownership of preventive materials such as ITNs. Poor regions also report high malaria case incidence. Unavailability of antimalarials is reported in lower-level facilities serving mainly the poor. Overall progress in improving key malaria indicators is poor. There is also no correlation between expenditure on malaria and the availability of ITNs $\left(R^{2}=0.6631\right)$. In conclusion, public financing for primary services such as malaria requires reforms to strengthen health sector performance in terms of sustainability, efficiency, effectiveness, and equity.

Keywords: Malaria, Public Finance, Uganda
\end{abstract}

Received: June 11, $2019 \quad$ Accepted: August 26, 2019

\section{Introduction}

The Uganda Vision 2040 aims to transform the Ugandan society from a peasant to a modern and prosperous country by the year 2040. To realize this vision, the Uganda National Development Plan (NDP) II is meant to steer the country toward middle-income status by 2020[1]. The pursuit of this goal has called for the transformation of the health sector to provide access to quality health care for all Ugandans through the delivery of promotive, preventive, curative, palliative and rehabilitative health care, with particular focus on primary health care. The drive toward Vision 2040 has precipitated a relatively rapid expansion of government spending catalyzed by a strong population growth rate and inflation. The increased spending by the Government of Uganda (GOU) has highlighted a number of high priority sectors but has been less beneficial to the health sector; i.e., of the Uganda Shillings (UGX) 
7.8 trillion increase in government spending between FY 2012/13 and FY 2016/17, the health sector got a mere $6 \%$ of the total share compared to about $21 \%$ for Works and Transportation sector, Education (13\%) and Justice, Law and Order (10\%), among other priorities[2]. Noting that the health sector is increasingly facing a heavy double burden of communicable and non-communicable diseases (NCDs) yet is critical to the achievement of Vision 2040, the expectation was that the sector would be accorded high priority in government spending.

To contain the growing burden of disease in Uganda, one of the key priorities for the government is malaria control. Malaria is one of the deadliest diseases in human history and its increasing burden in Uganda requires significant effort in funding and infrastructural improvements to bring it under control and set the country on the path of elimination. Based on the World Health Organization (WHO) guidelines, Uganda is still at the first stage of controlling malaria, let alone elimination. The high malaria burden in Uganda is self-evident: the World Malaria Reports of 2017 and 2018 state that Uganda is one of the 15 countries that contribute $80 \%$ of the global malaria burden $[3,4]$ and one of the five countries that accounted for nearly half of all malaria cases worldwide[4]. The main contributors to the malaria burden globally are Nigeria (25\%), the Democratic Republic of the Congo (11\%), Mozambique (5\%), India (4\%) and Uganda (4\%)[4]. In 2016, Uganda accounted for $4 \%$ of the global share of malaria cases and $3 \%$ of total deaths from the disease. Besides, Uganda reported a twofold increase in confirmed cases during 2015-2016 compared to 2013, which was largely attributed to inadequate vector control, improved reporting and climatic factors[5]. The World Malaria Report [3] confirms that Uganda is one of the countries experiencing increases in case incidence accounting for $17 \%$ of estimated malaria cases in East and Southern Africa.

As a major public health problem that is endemic in approximately $95 \%$ of Uganda, clinically diagnosed malaria is the leading cause of morbidity and mortality in the country, accounting for $30 \%$ to $50 \%$ of outpatient visits at health facilities, $15 \%$ to $20 \%$ of all hospital admissions, and up to $20 \%$ of all hospital deaths[5]. Deaths that occur at home, especially among children under five years of age, remain unreported. According to the MOH, Uganda has the sixth-highest number of annual deaths from malaria in Africa, as well as some of the highest reported malaria transmission rates in the world, with approximately 16 million cases reported in 2013 and over 10,500 deaths annually. Besides, there are socioeconomic implications including high out-of-pocket expenditure estimated to be between USD 0.41 and USD 3.88 per person per month (equivalent to USD 1.88 and USD 26 per household). Household expenditure for malaria treatment is also a high burden to the Ugandan population, consuming a larger proportion of the incomes in the poorest households [5, 6].

With the intervention of the President's Malaria Initiative (PMI) in 2005, Uganda has had some improvement in malaria control; however, a lot still needs to be done to build the capacity of the National Malaria Control Program to be able to progressively work toward reducing the malaria burden and establish structures for elimination. In this respect, the Ugandan Government policy goal is to reduce mortality due to malaria by $80 \%$ of the 2010 levels and reduce morbidity due to malaria by $75 \%$ of the 2010 levels. The key policy strategies toward this goal include timely and effective malaria case management, national scale-up of long-lasting insecticide-treated bed-nets, prevention of malaria in pregnancy, and indoor residual spraying[5].

The strategies outlined above require the significant mobilization of domestic funding and the consistency to improve national malaria outcomes, something which is not happening currently. In line with the 2001 Abuja Declaration and global estimates, Uganda's domestic financial contribution to 
malaria reduction needs to increase if this reduction strategy is to succeed. The Global Technical Strategy (GTS) for Malaria 2016 - 2030 estimated that global malaria spending would rise from about USD 3.9 billion in 2016 to USD 6.6 billion in 2020 to scale-up and sustain the control and elimination of malaria globally[4]. Sadly, these estimates have not been met; e.g. there was a funding shortfall of about USD 1.0 billion in 2016 which increased to USD 1.3 billion in 2017[4].

Based on these high global shortfalls, the response from high burden countries such as Uganda is critical because national financing is crucial to the financial requirements in malaria control and elimination. As much as malaria is preventable and treatable, progress worldwide has installed and more-so in high-burden countries. Responses to end malaria need to be more efficient, equitable and effective to be sustainable. This review aimed to examine how the Government of Uganda has directed public resources of the past four years or so to help address the malaria burden, in collaboration with development partners and private sources of funding.

\section{Methods}

This was part of a public expenditure review (PER) exercise for Uganda's Ministry of Health that took place from December 2017 to June 2018. The aim was to assess the performance of public expenditure planning, allocation, and execution processes in Uganda.

The main data sources were government reports including planning documents such as National Development Plan (I \& II), various national health accounts (NHAs), national demographic health surveys, and other reports such as the Uganda Medicines Price Monitor (2015). Regional reports included those from Medicines for Malaria Venture (2008), Coalition for Health \& Social Development (HEPS 2014) and Access, Bottlenecks, Costs \& Equity (ABCE) survey. Several national reports were downloaded from the webpages of the Uganda Bureau of Statistics (UBOS) and the Ministry of Health. Some of the global reports included in the review were the World Health Statistics (2017), World Malaria Report 2017 and the Global Fund report on malaria. Search strategies involved accessing specific webpages such as the Ministry of Health, Uganda Bureau of Statistics, World Health Organization as well as accessing data from Uganda's health management information system (HMIS). Additional data were searched using a combination of terms such as "malaria financing Uganda", "malaria budget Uganda", "malaria indicators Uganda" and "malaria report Uganda". A few data gaps were filled through key informant interviews although this was very limited. The analysis was mainly descriptive and involved looking at trends in budgetary allocations and financing of malaria and making correlations and inferences concerning sustainability, efficiency, effectiveness, and equity in financing and health outcomes. Findings were peer-reviewed by senior officials from the Ministry of Health (MOH), officers from the United States Agency for International Development (USAID) and the World Bank.

\section{Ethical approval}

Secondary data sources were used in the article so no ethical approval was required.

\section{Results}

\subsection{Financing sources and potential for sustainability}

Figure 1. and 2 present findings from an analysis of sources of funding for malaria in Uganda [710]. GOU funding has been relatively limited over the whole period, representing on average $10 \%$ of total malaria funding. Households represented about $67 \%$ of funding, while donors represented about $23 \%$ on average, signaling potential future problems for sustainability. 


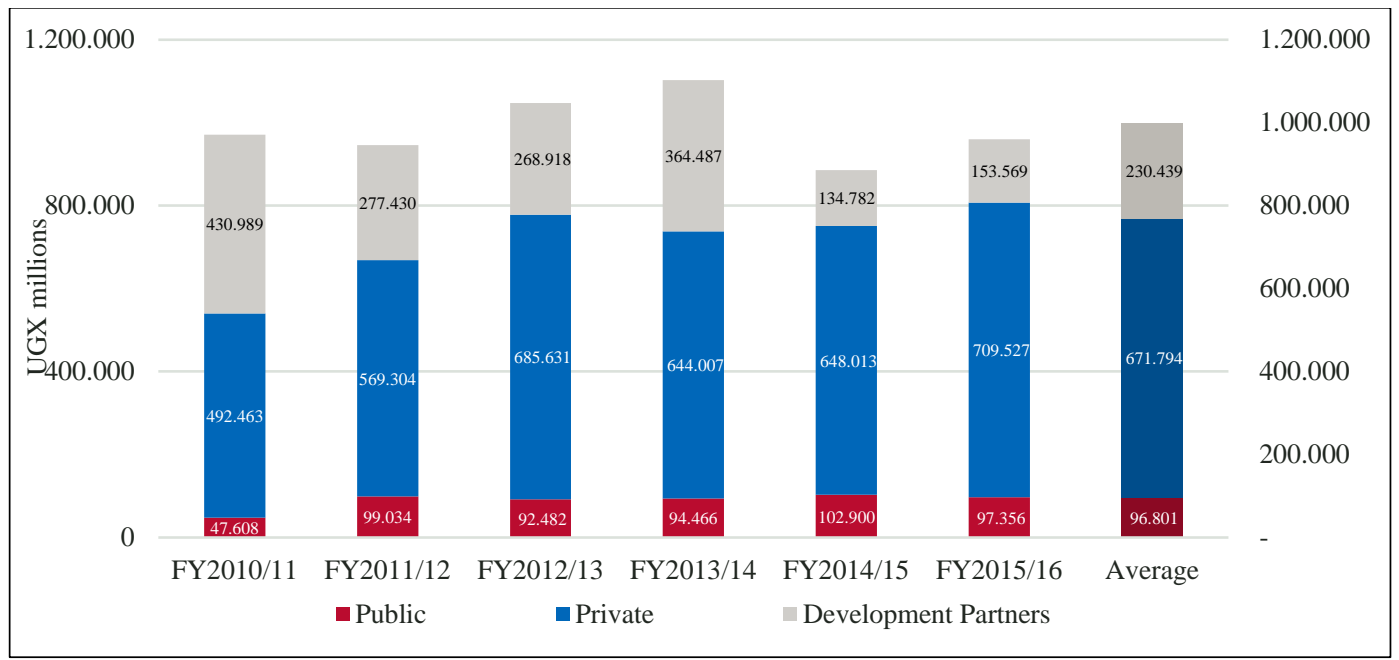

Figure 1: Sources of financing for malaria in Uganda Shillings (UGX) (2010 - 2016).

The NHAs suggest declining donor support for the malaria program yet there is no indication that the government is replacing donor funds with its funds. While government allocations to malaria programming rose from FY2010/11 through FY 14/15, they decreased in FY 15/16 in absolute figures and as a share of government budget; i.e. from USD 30.6m (UGX 102,900m) in FY2014/15 to USD 29m (UGX 97,400 million) in FY2015/16. Other sources of data such as the World Malaria Report [3] suggest increasing donor support for malaria programs in Uganda (Figure 2). The contradiction may be as a result of the difficulty to trace off-budget funds because of weaknesses in health information systems that fail to capture and standardize all data sources, and routinely monitor data quality. The main external malaria funders- Global Fund, PMI/USAID and the UK, increased their disbursement for malaria programs in Uganda from about USD71.3 million (UGX 239.6 billion) in 2014 to about USD125 million (about UGX 420 billion) in 2016, contrary to what is reported by the NHA for FY2015/16. Despite the stated increase in donor support, households still contribute significantly to malaria financing in Uganda which jeopardizes access to quality treatment for households

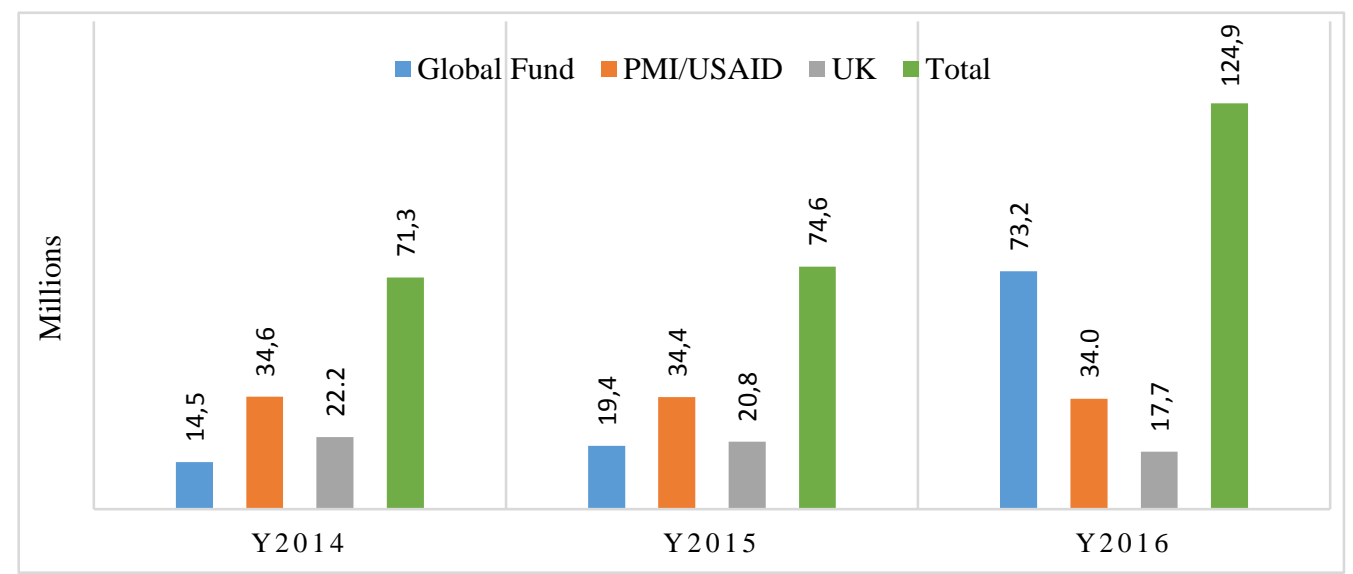

Figure 2: Main sources of donor financing for malaria Uganda- 2014 - 2016 (USD).

\subsection{Efficiency in financing malaria}

There is relative allocative efficiency as about $52 \%$ of the entire PMI budget goes into funding preventive activities which are in line with government policy to prioritize malaria prevention. About 
$29 \%$ funds curative care and 19\% of funds go towards other activities[11]. Global trends on allocative efficiency for malaria indicate that governments largely fund human resources for health which account for a global average of about $39 \%$ of government resources, planning, administration and overheads (17\%) and vector control other than insecticide-treated nets (ITNs) (18\%). The Global Fund, on the other hand, funds mainly ITNs $(43 \%)$ and treatment (21\%), among others. The PMI emphasizes expenditure on ITNs (35\%), other vector control measures (25\%) and treatment (20\%), among others [3]. These trends are consistent with the government strategy to put more emphasis on preventive measures. Figure 3 shows global malaria financing priorities until 2025[12].

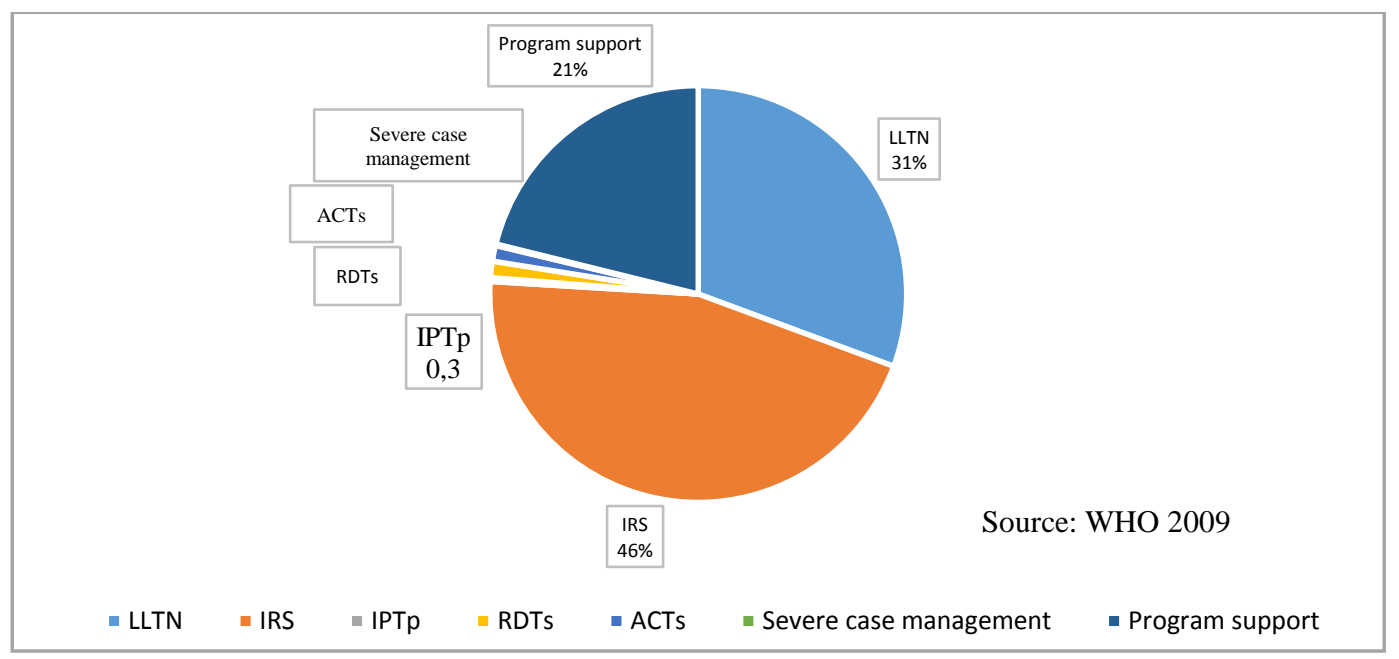

Figure 3: Global priorities in malaria financing by 2025.

As has been shown, Uganda government funding for malaria remains critical but minimal. The WHO[12] estimates that nearly $70 \%$ of total government funding for malaria goes into human resources and technical assistance, with medicines, insecticide and spray materials taking much of the remaining $30 \%$; meaning that very limited funds are allocated to the number priority area of prevention. Moreover, the World Malaria Report 2017 shows that per capita domestic spending on malaria across the East and Southern Africa region (excluding staff salaries and out-of-packet payments) is very low with Uganda spending USD 0.2 per capita. Overall, per capita funding for populations at risk decreased by $25 \%$ between 2011 and 2016 in Uganda[3], indicating that with decreased funding allocated for more deserving malaria-prone areas, the chances of a resurgence of malaria as already reported are real.

In technical efficiency, the cost of malaria medications (ACTs) represents an opportunity for improved efficiency. The main driver of malaria treatment cost is the number of players in the supply chain including the importer, wholesaler and outlet/retailer (e.g., pharmacy, drug store or clinic). The mark-ups added at each supply chain step contribute significantly to price variations by sector and region. In some cases, the overall mark-up in private clinics compared to other outlets is as high as $325 \%$.

Malaria treatment unit costs and prices also vary in public facilities; e.g. cost and prices in hospitals vary from about USD 4.46 to USD 9.52 respectively compared to Health Centre II where costs and prices vary between USD 2.52 and USD 3.57 respectively. The high variations represented by hospitals are likely due to payments for high cadre health workers such as doctors and other specialists.

Elsewhere, failure to effectively implement a private sector co-payment mechanism has affected access to subsidized anti-malarial medicines in private health facilities, pharmacies, and drug shops. As 
a result, medicines are sold at USD 1.49 (UGX 5,000) beyond the recommended price of USD 1.04 (UGX 3,500) [13]. Overall, even though all health facilities (public and private) report that up to $90 \%$ and above have ACTs available[14] (Figure 4), being a first-line treatment for uncomplicated malaria means that many Ugandans still cannot access treatment as some facilities have not stocked ACTs. The other antimalarials are poorly stocked in all sectors; however, the public sector has the lowest availability of quinine injections with only $38 \%$ of facilities stocking the medicine.

Anti-malarial sales in private facilities remain unaffordable for ordinary Ugandans; e.g. as demonstrated in Figure 4, the lowest-paid Ugandan government worker spends $80 \%$ and $72 \%$ of a day's wage to be able to purchase ACTs from private-for-profit and private-not-for-profit facilities, respectively. There is also remarkable inefficiency in the use of anti-malarials especially first-line ACTs for treatment of uncomplicated malaria. The MoH's management information system indicates that up to $43 \%$ of patients reporting fever are treated with malaria without confirmed diagnosis and/or after negative laboratory results. This also raises the risk of resistance. A policy revision to allow testing using rapid diagnostics kits at private drug outlets has been initiated to reduce presumptive treatment for malaria[15].

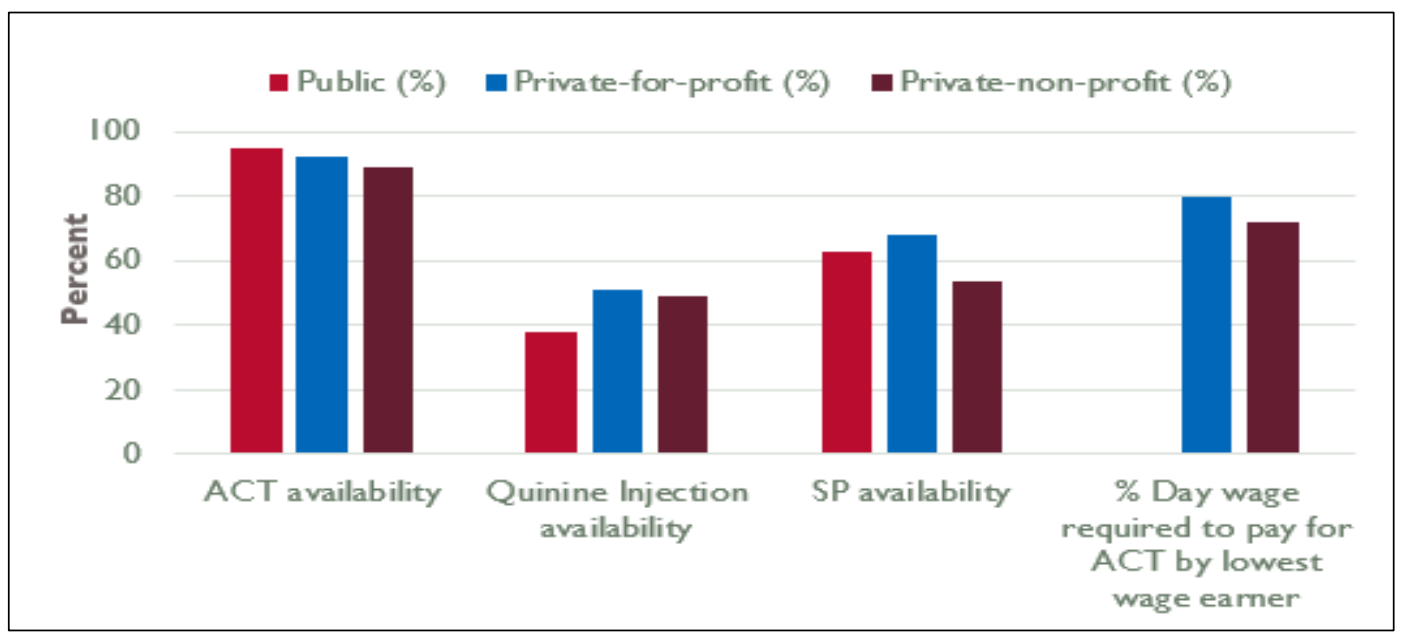

Figure 4: Availability and affordability of anti-malarials.

\subsection{Equity}

The Uganda Malaria Quarterly Bulletin 2016[16], indicates inequities in malaria incidence across the fifteen regions. The worst affected are Eastern, Karamoja, North and southwest regions which experienced increases in malaria incidence ranging from $19 \%$ in the East to $120 \%$ in the North. Karamoja had $44 \%$ increase and the North West experienced a 100\% increase. The rest of the regions experienced decreases in malaria incidence between $-3 \%$ and $-72 \%$. There is a likely correlation between high malaria incidence rate and poverty as the regions reporting the high incidence rates also have the highest poverty rates ranging from $70 \%$ to $80 \%$ of the population living below the international poverty line[17]. Other reasons to explain the differences in malaria control strategies could be linked to community responses to these strategies including ownership and actual use of ITNs. Karamoja region, in particular, has the lowest ownership of ITNs (55\%) compared to the rest of the regions where ITN ownership range from $72 \%$ of households in Bugisu to $92 \%$ in West Nile[18].

Differences in ITN ownership are also reported between rural and urban households and between wealth quintiles. Per the most recent household survey[19], ITN ownership in the poorest households 
stands at $71 \%$ compared to $84 \%$ in the richest households. In terms of treatment for malaria, higher costs in hospitals than in lower-level facilities likely benefit the poor and rural who tend to utilize the lowerlevel facility services. However, a report by Medicines Transparency Alliance[20] indicates that all types of health facilities in rural areas where the majority of poor Ugandans live have lower availability of medicines than urban areas.

In areas where there is not a public facility nearby, or when medicines might not be available at public facilities, private (for-profit and non-profit) health facilities may be the main service providers. Because services from such facilities are based on ability to pay rather than need, the poor may not be able to access malaria treatment services. Data from the Uganda Medicine Price Monitor demonstrate that the prices for a round of malaria treatment (Artemether/Lumefantrine tab 20/120mg) has fallen in private facilities from more than an average day's wage in 2013 to about 0.72 days' wages in 2015 but costs in mission facilities rose from 0.6 days' wages to about 0.8 days' wages (Figure 5) [16]

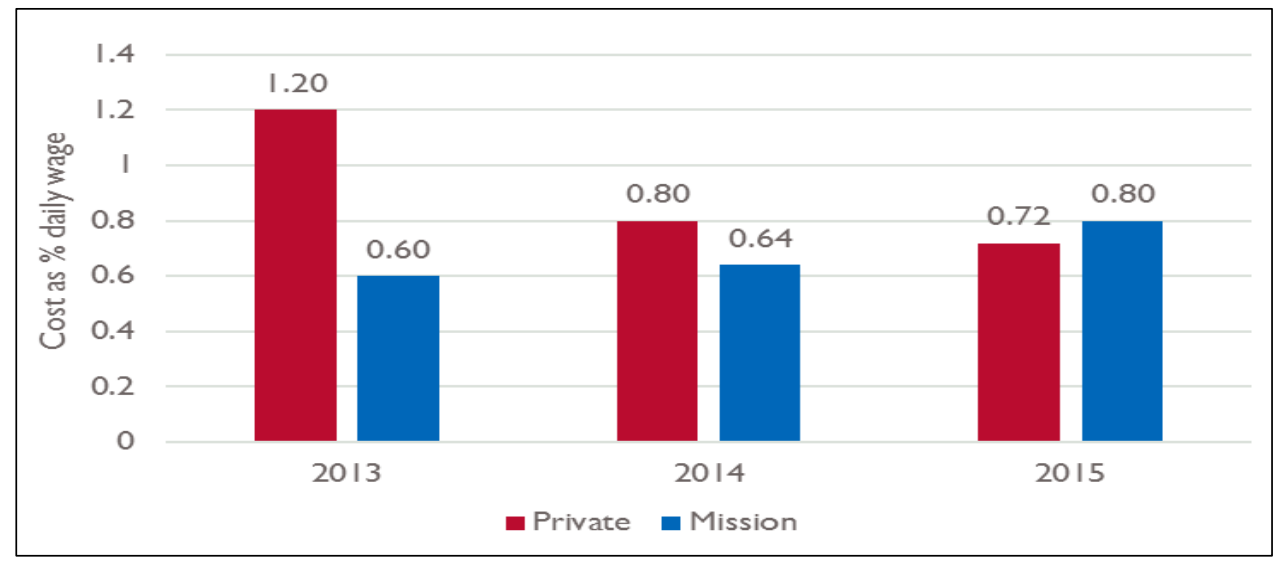

Figure 8: Costs of Malaria treatments in non-GOU facilities (\% daily wage).

Price decreases in private facilities will likely improve access to malaria commodities but the opposite is true in mission facilities where prices have been on an upward trend between 2013 and 2015 $[14,21,22]$.

\subsection{Effectiveness}

As noted above, much of the envelope of government funding for malaria control and treatment is directed toward human resources and technical assistance at the expense of treatment and prevention programs. While this support has resulted in strong improvement in malaria reporting[18], progress on improving key indicators such as case incidence, admissions, and mortality is mixed (Figure 6). 


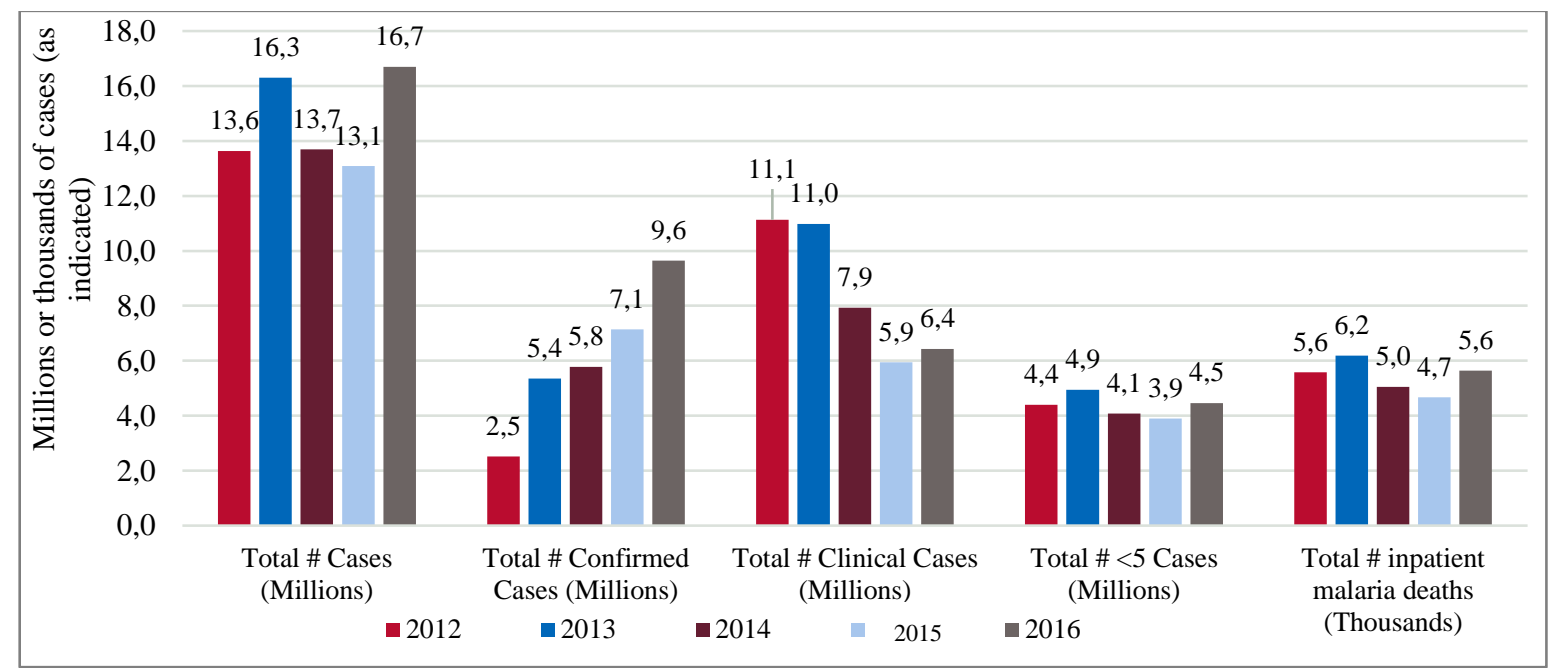

Figure 6. Key malaria case indicators.

From Figure 6, the malaria control interventions have not been effective in reducing malaria cases and related mortality to set the path for elimination. The total number of malaria cases increased from 13.6 million in 2012 to 16.7 million in 2016. spiked in 2013, rising from about 14 million in 2012 to 16.3 million. The rapid decline to 13.1 million cases reported in 2015 down from 16.3 million cases in 2013 was due to significant investments in vector control. These gains were reversed in 2016, when malaria cases spiked again to about 17 million, signaling lack of investments in malaria control and inconsistency in the rollout of interventions. Over the same period, the total number of confirmed cases also rose from 2.5 million in 2012 to 9.6 million in 2016. Although this could be partly due to improved diagnostics, there is no concrete evidence to support this suggestion because investment in diagnostics has been very limited. Other indicators such as inpatient mortality have been variable; e.g. in 2012 inpatient mortality was about 5,600 deaths, which declined to 4,700 in 2014 but then rose again to about 5,600 in 2016. It is noteworthy that the negative outcome indicators correspond with a period of declining government funding for malaria programs where key interventions such as ITNs and IRS did not seem to get priority in funds allocation. There is a positive relationship between increased spending and the reported availability of ITN, as demonstrated in Figure 7.

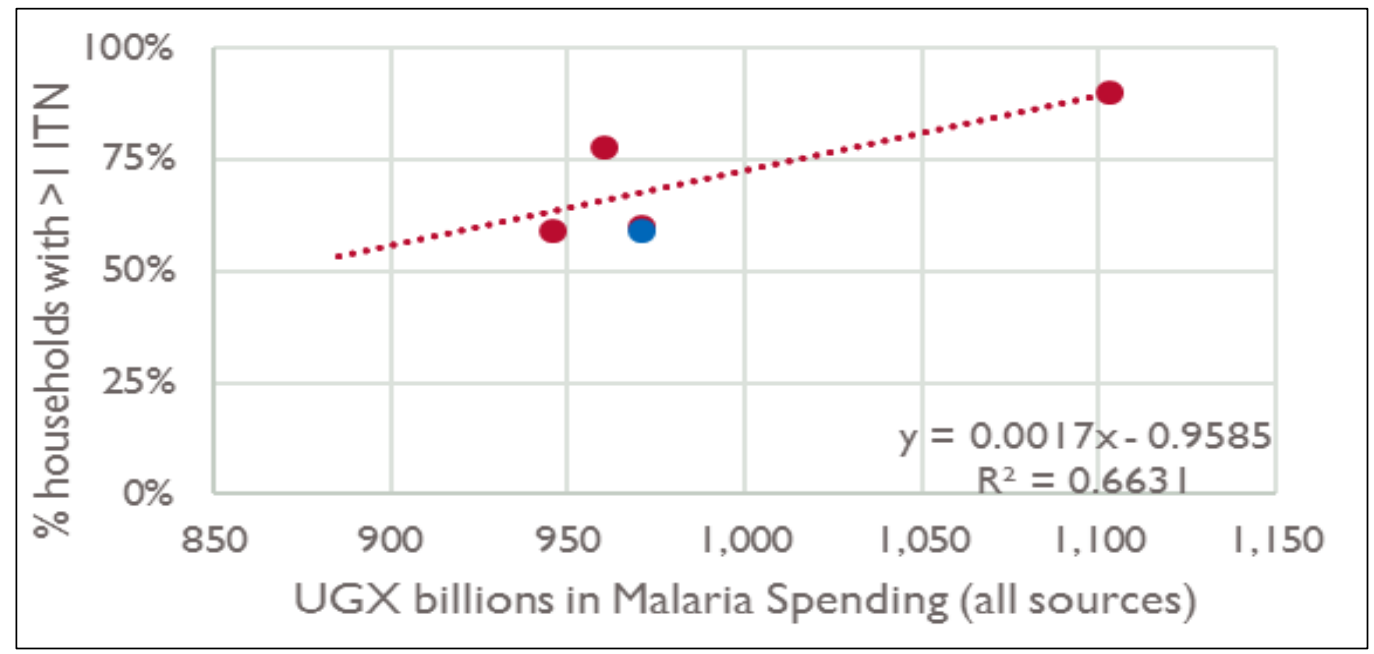

Figure 7. Correlation between spending on malaria and the availability of ITNs. 
Increased spending does not, however, have a strong direct relationship with reduced inpatient malaria deaths as there appears to be a slight positive relationship between the two factors (Figure 8). This may indicate that spending tends to be responsive to increases in malaria mortality rather than the inverse.

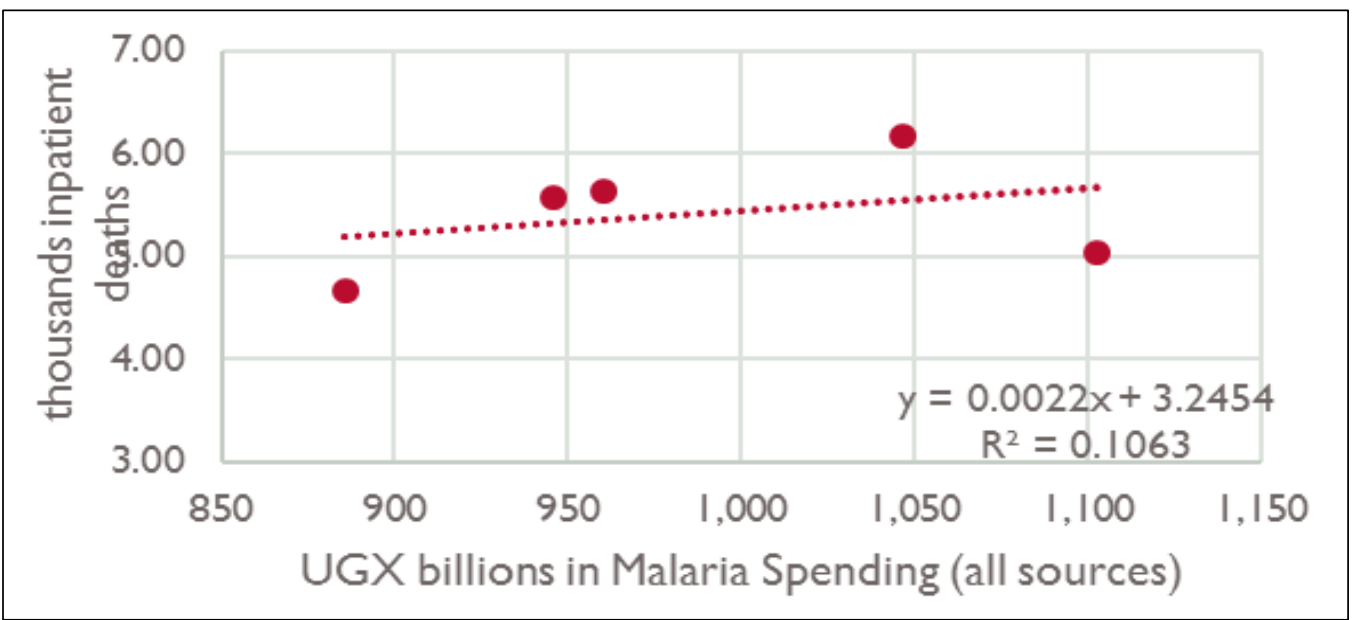

Figure 8. Correlation between spending on Malaria and in patient malaria deaths.

Gaps in the availability of medicines and testing materials at the facility level may explain some of the mixed results on the effectiveness of malaria prevention and treatment programs. Effective case management of malaria requires that health facilities have both malaria treatment and diagnostics on hand to identify cases of malaria and provide treatment. The 2014 report on the ABCE survey [23] found that while malaria diagnostics were widely available, there appear to be gaps in the availability of either ACTs or diagnostics -, particularly at lower-level facilities (Figure 9).

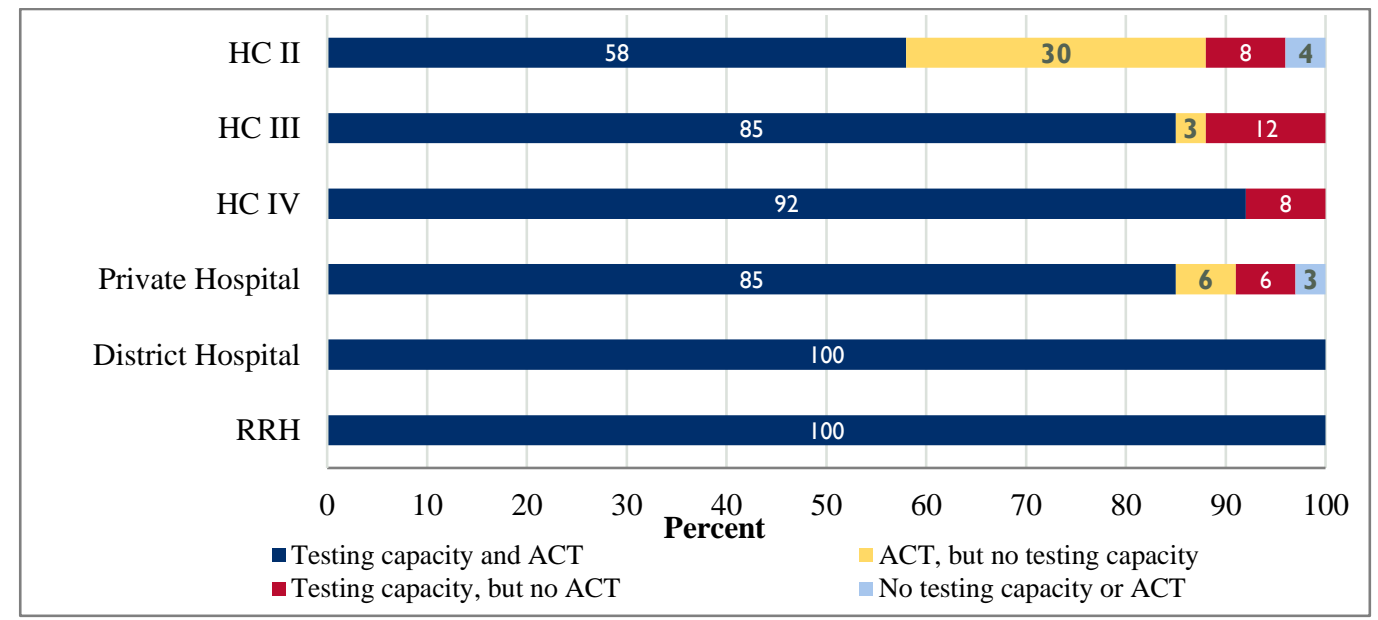

Figure 9. Availability of equipment and supplies to provide malaria health services.

Effectiveness of malaria control would benefit from strengthening primary care level facilities as well as ensuring that preventive interventions reach and are utilized by communities in rural areas. 


\section{Discussion}

The Government of Uganda has clear policy objectives with regard to malaria control and work toward the elimination of the disease. These objectives are articulated in the long-term health sector strategy outlined under Vision 2040. Part of the planned reforms under Vision 2040 includes improvements in primary health care as a basis for achieving universal health coverage (UHC), which is key to addressing some of the noted health disparities in Uganda. There is, however, a disconnect between government professed policy reforms in malaria control and elimination which emphasize preventive measures, and the trajectory of public funding for malaria and the health sector as a whole; for instance, the government allocates limited funds for malaria programming most of which go into salaries and wages. To effectively control malaria, it is strongly recommended that the government undertakes reforms in domestic resource mobilization and allocation towards malaria in particular and the health sector as a whole. At the global level, financing for malaria has consistently failed to meet its funding targets in the recent past, which should be a wake-up call for Uganda to initiate fiscal reforms to increase domestic funding for malaria. In 24 out of 41 high-burden countries which rely heavily on donor support for malaria programs, the per capita funding for at risk populations declined in 20152017 compared to 2012-2014[4]. Although Uganda experienced the lowest decrease in per capita funding $(1.0 \%)$ over the stated period, the main sources for funding for malaria in the country (donors and household out-of-pocket) are unsustainable, inequitable and inefficient. They are not only unpredictable for programming purposes but also fragmented to place the financing burden on individual households and therefore cannot meet the long-term UHC goals. Fragmentation in health financing has been variously discussed as detrimental to health financing goals[24-27]. To reduce the fragmentation in health financing in Uganda, there is an urgent need to reinforce domestic funding for malaria activities, both by increasing the level of GOU funding and by allocating more of the GOU resources toward direct service delivery activities to reduce dependence on external funding and OOP payments. The need for improved domestic financing for the health sector has been emphasized as a means of mobilization additional resources and financial sustainability[28, 29].

Globally, about $77 \%$ of funds for malaria control and elimination go into purchasing long-lasting treated nets (LLTN) and indoor residual spraying (IRS)[12]. This is consistent with the goal to strengthen primary care delivery systems and position countries for UHC. The GOU needs to realign its expenditure on malaria with national and global priorities in malaria financing. Such realignment will improve efficiency in malaria programming. Also, improvements in technical efficiency, for example, would require strategic reforms in the commodity purchasing including a reduction in the number of players and price monitoring to ensure availability of essential commodities, particularly in lower-level facilities. Price monitoring will also promote the affordability of malaria drugs outside government facilities. In addition, the GOU is encouraged to make funding at facility level available for the purchase of equipment and supplies to provide malaria services, particularly for health center (HC) III and below. Strongly encouraged are initiatives to reduce the unit costs of malaria medicines and treatments, particularly for ACTs, in both public and private facilities and promote more targeted use of antimalarials to improve treatment efficiency.

Targeted use of anti-malarials includes test diagnosis before treatment to eliminate presumptive treatment. Treatment without test in public facilities is a common problem in sub-Saharan Africa but one that has remarkably improved over the years; e.g. in 2010 less than $40 \%$ of patients were treated after a diagnostic test but this improved to about $87 \%$ as of 2016[3]. However, in Uganda, the proportion 
of suspected cases in public facilities receiving a diagnostic test before treatment is below 60\% [18]. Improvements in diagnostic testing before treatment of malaria, therefore, constitutes a significant costsaving area for the GOU.

As part of the reforms to ensure efficient and sustainable health programs and systems, the GOU needs to implement strategic purchasing of health services. Strategic purchasing, as an effort to improve health system performance, is an important reform objective in LMIC that aspire to achieve UHC[30, 31]. It involves three key elements, namely; aligning population health needs with services provided whilst accounting for national priorities and evidence on cost-effectiveness, effective provider contractual mechanisms, and payment systems, and accounting for provider levels of quality and efficiency[30]. The current status of purchasing in Uganda is passive involving mainly the government paying the bills without any contractual engagements on provider performance. Strategic purchasing coupled with increased domestic funding for malaria would help in addressing the inequities noted in malaria control in Uganda, particularly the malaria case incidence and ownership of ITNs.

Whilst medicine prices favor the poor, i.e. prices are lower in primary health facilities than in hospitals, these medicines are often unavailable in these facilities serving the poor. Lack of commodities in facilities that serve the poor expose this population group to catastrophic costs with potential for further impoverishment. Besides, the cost of purchasing a full dose of anti-malarials from nongovernment facilities is prohibitive for low-income earners, as it constitutes up to $80 \%$ of the daily wages of the lowest-paid worker. Improving access to medicines for the poor is a health system priority and has been variously emphasized in health system reforms [32-35].

As far as the effectiveness of malaria control interventions is concerned, viewed in terms of processes and health outcomes, there is a need for drastic improvements beyond the first stages of malaria control current in Uganda. Government investments have contributed to improved malaria reporting but not much else. Key malaria outcome indicators including case incidence, admissions, and mortality have not changed and in some cases have worsened.

In conclusion, malaria control structures in Uganda and specifically public financing at $10 \%$ of total malaria funding, remain too weak to allow the country to make progress toward elimination. All the indicators including those for sustainable financing, efficiency, equity, and effectiveness, are fragile suggesting that even at the early stages of malaria control, Uganda is still not making much progress. With $67 \%$ of malaria funding coming from households, the financing mechanism is not sustainable. A re-prioritization of malaria control efforts needs to be considered as a step toward strengthening primary health care delivery systems and contribute to UHC. As data shows, on average, national governments globally are the second largest contributor to malaria financing, which confirms the capability of most countries to mobilize the financial resources to attain some level of universality, particularly of most essential services such as malaria control and other primary health care services. For Uganda and many other developing countries, while the economic growth rate is essential, they are particularly encouraged to invest more in policy reforms to expand domestic resources and invest in providing quality primary health care services.

\section{Acknowledgment}

Funding for the project was from USAID and implemented by Nathan Associates, Inc. We thank the following for their participation in the management of the project and data collection: Mr. Enock Mwami, Mr. John Kauta, and Mr. Joseph McGrann. 


\section{References}

[1] Government of Uganda, "Second National Development Plan (NDPII) 2015/16 - 2019/20: Uganda Vision 2040- A Transformed Ugandan Society from a Peasant to a Modern and Prosperous Country within 30 years", Government of Uganda (GOU), Kampala, 2015.

[2] Uganda Bureau of Statistics, "Statistical abstract", Uganda Bureau of Statistics, Kampala 2017.

[3] WHO, "World Malaria Report", World Health Organization, Geneva, 2017.

[4] WHO, "World Malaria Report", World Health Organization, Geneva, 2018.

[5] Ministry of Health, "Malaria Control Program", Ministry of Health, Kampala. Available:http://health.go.ug/programs/national-malaria-control-program2018.

[6] Ministry of Health, "Malaria Indicator Survey (MIS) 2014-15", Government of Uganda, Kampala, 2015.

[7] Ministry of Health, "National Health Accounts: Financial Years 2010/11 \& 2011/12", Government of Uganda, Kampala, 2012.

[8] Ministry of Health, "Uganda Health Accounts: National Health Expenditure- Financial Years 2010/11 and 2011/12", Government of Uganda, Kampala, 2014.

[9] Ministry of Health, "National Health Accounts: Financial Years 2012/13 \& 2013/14", Government of Uganda, Kampala, 2015.

[10] Ministry of Health, "National Health Accounts 2015/16," Government of Uganda, Kampala, 2017.

[11] President's Malaria Initiative, "PMI Malaria Operational Plan FY2018", PMI. Available: https://www.pmi.gov/docs/default-source/default-document-library/malaria-operational-plans/fy2018/fy-2018-uganda-malaria-operational-plan.pdf?sfvrsn=112018.

[12] WHO, "World Health Organization. Global health risks: mortality and burden of disease attributable to selected major risks", World Health Organization, Geneva, Switzerland, 2009, Available:

http://www.who.int/healthinfo/global_burden_disease/GlobalHealthRisks_report_full.pdf.

[13] Coalition for Health Promotion \& Social Development (HEPS), "Cost and Pricing: An Assessment of Private Health Facilities in Uganda", Cardno Emerging Markets Ltd., USA. Available: http://uhfug.com/wp-content/uploads/2017/04/An-assessment-Of-Private-Health-Facilities-InUganda.pdf2014.

[14] WHO, "Medicine Price Monitor for Uganda No. 13: May-June 2015", World Health Organization. Available: http://apps.who.int/medicinedocs/en/m/abstract/Js22317en/2015.

[15] The Global Fund, "Audit Report: Global Fund Grants to the Republic of Uganda", Global Fund, Geneva, 2016.

[16] Ministry of Health, "Uganda Malaria Quarterly Bulletin", Government of Uganda, Issue 14, 2016.

[17] National Malaria Control Programme \& INFORM Project", An epidemiological profile of malaria and its control in Uganda". Available: http://www.inform-malaria.org/wpcontent/uploads/2014/05/Uganda-Epi-Report-060214.pdf," 2013.

[18] Uganda Bureau of Statistics and ICF, "Uganda Demographic and Health Survey 2016: Key Indicators Report", Uganda Bureau of Statistics (UBOS) and ICF, Kampala, Uganda and Rockville, Maryland, USA, 2017.

[19] Uganda Bureau of Statistics, "The 2016/17 Uganda National Household Survey", Uganda Bureau of Statistics (UBOS), Kampala, 2017. 
[20] G. Stedman-Bryce, F. Schatz, C. Hodgkin, and P. Balogun, "Medicines Transparency Alliance (MeTA) Evaluation: Testing MeTA's underlying intervention logic", e-PACT., Available: http://haiweb.org/wp-content/uploads/2016/11/Medicines-Transparency-Alliance-MeTAEvaluation.pdf2015.

[21] WHO, "Medicine Price Monitor for Uganda No. 11: July - September 2013", World Health Organization.

Available:http://apps.who.int/medicinedocs/documents/s21906en/s21906en.pdf2013.

[22] WHO, "Medicine Price Monitor for Uganda Uganda No. 12 July-September 2014", World Health Organization.

Available:http://apps.who.int/medicinedocs/documents/s22316en/s22316en.pdf2014.

[23] IHME, "Assessing Facility Capacity, Costs of Care, and Patient Perspectives", University of Washington, Seattle.

Available:https://www.healthdata.org/sites/default/files/files/policy_report/2014/ABCE/Uganda/ ABCE_Uganda_full_report_2014.pdf2014.

[24] D. McIntyre and J. Kutzin, "Health financing country diagnostic: a foundation for national strategy development", in "Health Financing Guidance No. 1: WHO/HIS/HGF/HFGuidance/16.1", World Health Organization, Geneva, 2016.

[25] WHO, "Sustainable health financing, universal coverage, and social health insurance. World Health Assembly Resolution WHA58.33", World Health Organization, Geneva, 2005.

[26] G. Carrin and C. James, "Reaching universal coverage via social health insurance: key design features in the transition period [Discussion paper no. 2]", World Health Organization, Geneva, 2004.

[27] D. McIntyre, "Pay the piper and call the tune: changing health care financing mechanisms to address public-private health sector mix inequities", (The economics of health equity. Cambridge: Cambridge University Press, 2007.

[28] WHO, "Domestic resource mobilization for sustainable financing for health in Africa African Region. Working Paper prepared by the WHO Regional Office for Africa", World Health Organization, Geneva, 2017.

[29] R. Tamarappoo, P. Pooja, R. Muthu, and F. Jincy, "Analysis of the linkage between domestic revenue mobilization and social sector spending: Phase 1 Final Report Leadership in Public Financial Management II (LPFM II)", Nathan Associates Inc., 2016.

[30] R. Busse, J. Figueras, R. Robinson, and E. Jakubowski, "Strategic purchasing to improve health system performance: Key issues and trends", Healthcare Papers, Vol. 8, Special Issue, 62-76, 2006.

[31] RESYST. (2014). What is strategic purchasing for health? Available: https://resyst.lshtm.ac.uk/sites/resyst/files/content/attachments/2018-08-

22/What\%20is\%20strategic\%20purchasing\%20for\%20health.pdf

[32] T. Bright, L. Felix, H. Kuper, and S. Polack, "A systematic review of strategies to increase access to health services among children in low and middle-income countries", BMC Health Serv Res, 17(1), 252, 2017.

[33] A. Cameron, M. Ewen, D. Ross-Degnan, D. Ball, and R. Laing, "Medicine prices, availability, and affordability in 36 developing and middle-income countries: a secondary analysis", Lancet, 373( 9659), 240-249, 2009. 
[34] K. M. Leisinger, L. F. Garabedian, and A. K. Wagner, "Improving access to medicines in low and middle-income countries: corporate responsibilities in context", South Med Rev, 5(2), 3-8, 2012.

[35] Y. Lu, P. Hernandez, D. Abegunde, and T. Edejer, "The World's Medicines Situation", Available: http://digicollection.org/hss/documents/s18767en/s18767en.pdf2011. 